\title{
VEINTE VOCES PARA UN NOMBRE. ARTEFACTAS ${ }^{1}$
}

\author{
Cristina Morales Saro ${ }^{2}$
}

I.

Su voz, esa voz, dónde ha ido a parar

Su aquí tan fugaz que no

ser completo, inigual.

II.

Mujeres por la calle cada día

que cruzan sus miradas con la mía

desde la retaguardia, tantas veces

desde el frente, desde el frente.

Mujeres que por los ojos

avanzan de vida en vida

e invocan la sed debida

sin detenerse, sin detenerse.

Mujeres por sus ropajes

por su piel, por sus entrañas

${ }^{1}$ Fecha de recepción: 24/10/2016.

Fecha de aceptación: 26/10/2016.

${ }^{2}$ Cristina Morales Saro (Madrid 1982) es doctora en Filosofía en el área de Estética y Teoría de las Artes y se desempeña como docente e investigadora en la escuela de literatura de la Universidad de las Artes del Ecuador. Publica artículos, ensayos, poesía y literatura infantil. Destaca la monografía Problemas de filosofía estética volumen I. Arte y lenguaje (Publicia 2015) y los ensayos Entre la teoría y la praxis. La estética de la condición humana desde la ética aristotélica al pensamiento de Benedetto Croce. Lógoi.

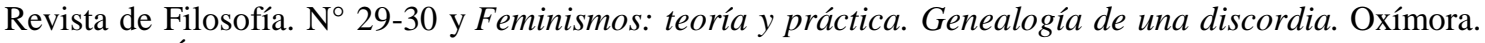
Revista de Ética y Política. $\mathrm{N}^{\mathrm{o}} 7$. Algunos de sus poemas han sido publicados en diversas antologías como Desnuda en la Complilación de la $2^{\text {a }}$ Convocatoria Internacional de Mujeres Poetas; o Cambio, crisis, duración, memoria, movimiento. En la antología del I Concurso de Poesía "Por amor a la poesía" (Letras con Arte 2014). Se puede ampliar información sobre sus actividades en www.lamaquinanoematica.wordpress.com; $\bowtie$ aleteando04@yahoo.es. 
mujeres desde el alba.

Mujeres desde el sueño

guardián de qué emboscada

retrocede, retrocede.

III.

Mujer hecha de carne y de leche,

lejos de tu hoguera, lo blando de los cuerpos

te espera, te puede.

Abre una vez más de tu melena

los cien mil brazos

y esparce su influencia

por todos los rincones.

Mujer de cálido regazo

acoge si llegas

este cosmos desorganizado.

Que a tus pies se postren

todas las banderas

que nada quede fuera

que no te colmen.

IV.

Criatura, espera.

No ves que lo de fuera

no puede asimilarte.

Desciende, arresta, 
que tus hijas ya se enganchan

a la tierra con más fuerza.

Desmiente, empodera

que tu imagen no subvierta

a toque de corneta

el dolor establecido por cualquiera.

No crezcas,

las condiciones no son buenas

lo demás es como siempre

espera, espera.

V.

Desde las antípodas de un cuerpo organizado

hablaron un día las hormigas

de un comienzo nuevo.

Y ese fue el principio de tu magma

del que surgen espontáneas

las diversas imposturas.

Cae la noche sobre el límpido

lucir de las baldosas

y las calles

se pliegan al ir y al venir hostil del trabajo.

Cae la noche sobre el ídolo carmín

y las huertas se declaran en huelga

de fecundidad,

como las brujas. 
VI.

Tras el mínimo gesto me ofreces

las vidas multiplicadas de las mulas

que han cargado, día a día, con todo.

Y esbozando futuro, se alejan

las medidas de los párpados

y las comisuras de los labios.

Abierta, así te quieren en casa

hermana.

Abierta, desparramada.

Y la voz burlándote

lasciva, al oído

y el amor bordándote

adornos sin hilo.

Desempolva, hermana, el vestido.

VII.

Despacio las barreras y la plaza

se van alejando cada vez mas

y llega un momento en se que decide

de que lado estás.

El ruedo sin asiento y arrojado

la tarima sin consuelo y a recaudo

nada fría que pudiese articularlos.

Atomizados los lugares, los espacios 
retroceden y se achican.

Y a cambio, ideas fijas

nos pueblan las cabezas de agujeros.

El tejido ha sido desde siempre

cosa nuestra, y realza

el hilo que entretiene y amenaza.

VIII.

Fantasías, muchas, de alegría

y vino a rebosar

y cánticos y flores.

Y un vértigo abismal

por nuestras hijas

y fuerza colosal

en las rodillas.

Fantasías, muchas, de un día

en que dar de mamar

actúe como principio

de regulación social.

Y un ansia de libertad infinita

para ser como somos

y nada menos y nada más.

IX.

Marina sueña con ser escritora

su última novela relata la aventura

de una niña como ella 
reclusa en algún lugar indeterminado.

La trama, por supuesto, la trazan

los periplos hacia la liberación

en los que interviene, a favor,

otra mujer, algo mayor.

Marina terminó sus estudios de primaria

y ganó dos medallas en natación

y escribió un diario de esos días

para que nunca se le olvidaran.

Un día trajo sus cuadernos

y me los leyó.

$\mathrm{X}$.

Carla no podía entender

por qué para encontrar las palabras

en el diccionario de alemán

había que buscarlas en masculino.

Debió ser que el lenguaje,

lo inventaron los hombres

argumentó Davi

en encendido debate.

Imposible, no tienen tanta fuerza

como dicen,

intervino Ale,

quizá lo manipularan. 
En todo caso, ellas aprendían

que lo femenino era una marca.

XI.

Desatada, sin posibilidad de contagio

la sociedad humana

deshabita el mundo a cada rato

dejándolo desierto e intacto.

Y con él, desaparecen las acciones

y la gloria y la historia y el verso.

Y en él, se ahoga la palabra

el sentimiento, el sendero.

Mundo, inmundo desconcierto

que desalma lo que toca.

Mundana condición de nuestro ser

qué vendrá después de lo infrahumano

a roernos las manos, los brazos,

los senos, las ideas y los pies.

XII.

Con cuidado, nos tienen donde quieren

las trampas, $\tan$ bien hechas, tan dispuestas

con mil ojos, nada es como parece

solo esperan a una incauta cualquiera.

Mira bien al salir y mejor al entrar

que ya arrecia un ser y la tensión muscular

activa la alarma por delante y por detrás 
inunda de ruido el paseo habitual.

No hay nada que hacer ni lengua moral

que explique a los nervios cómo han de actuar

silencio a lo sumo, callar ritual.

No hay luz para lo inerme que queda

ni palabra ni poética que pueda

ni pala más eficaz de desescombro.

XIII.

Hábitos, son hábitos que se instauran

y se quedan habitándonos

hábitos que son vestidos

de muerta.

Hábitos, que nos preparan

que nos predicen

que nos enseñan

pendientes del momento

en que se cumplirá completamente

la pasividad total

en cuya impropiedad

nos hemos hecho

y nos hemos deshecho

tantas veces.

XIV.

La voz, esta voz

que permite 
que entre tu y yo

se pueda respirar

es un hilo de voz

nada más

que va y que viene.

Un hilo que vamos tejiendo

que se ensancha y nos arropa

cobijo, qué paradoja,

que pende de un hilo.

XV.

Casi casi me conformo con las cosas

sobretodo prescindible,

útil, también eficaz o válida.

Pero siempre en posición de desventaja

demostrando lo útil y válida que puedo ser

para asegurarme de que no prescinden de mí

con uñas y dientes.

La balsa se mueve y amenaza

todo el rato

y es imprescindible concentrarse.

No entiendo nada

tanto esfuerzo

a cambio de equilibrio sólo

a cambio sólo de esperanza. 
XVI.

Estas vidas, que han cambiado tan rápido

y que dejan ese su sabor dulce amargo

nos enseñan aún su acontecer inaudito

nos amarran sin más en la unicidad del respiro.

Cada vida, consciente o aterrada de estar viva

cada una una simiente, un horizonte

cada una de las veces que no expira

$\mathrm{y}$ todas juntas la corriente, el sin nombre.

Cada día cuántas vidas ve pasar sin su hábito

cada vida cuántos días tiene a buen recaudo

y cuántos han pasado sin dejar apenas rastro.

Cada día de la vida pesa un poco más

pero cada vida en un día puede cambiar

¿No es verdad?

XVII

Nada desmiente el simulacro ante el espejo

da igual que te cortes o te tiñas el pelo

da igual que te pongas o te quites un miembro

da igual que orientes la luz para realzar tu lado bueno.

Nada dispone que se pueda, el triunfo se pelea

por dentro, desde fuera. Fiera, cautela.

Nada sostiene el suelo y apega

nada centellea y se esconde, nada atraviesa.

Nada desciende al submundo y regresa 
nada nos besa cuando alguien se acerca

nada nos puede, por las rodillas, aviesa.

Nada desmonta, centímetro a centímetro

las construcciones de "los hombres"

nada infinito, nada, efímero.

XVIII.

Inciden, ancora, compañera

en despoblarme.

Retuercen otra vez los argumentos,

hacen ruido.

Insisten en que la naturaleza

se empeñó en distinguirnos.

Asienten ante la fuerza

caminan por el camino

jadean o no jadean

dejan huellas.

Bajo el yugo de uno

van cayendo

su fe, su afamada sed,

su último verdugo.

XIX.

No transijo, habladuría la palabra

es sencillo, aposentados como estamos

no nos damos cuenta de nada de lo que pasa. 
No respiro, tu sierva espera, como siempre

no me cansa, es la fatiga de tu abrigo

no me abrasa la simiente.

Y se esparce aleatorio el ser aparte

y la huida de los bosques por completo

despedida en desconsuelo va una madre.

La memoria desorientada, en hechizo

siempre un paso o dos por delante, a un suspiro

de alcanzarse.

XX.

Mujer, mujer, mujer diferenciada

cuantas veces en tu mano la guadaña

que separa ha desmentido uno por uno

los motivos que te ataban.

Mujer, mujer, mujer en la palabra

cuando el gesto te lo inventas, habla

y te figura un maniquí tan obtuso

que no logras decir nada.

Mujer, mujer, mujer fuera de quicio

cuánto tiempo alargarás el sacrificio

de los días y las horas achicadas,

en éste tu existir tan raquítico.

Mujer, mujer después de tantos nombres

como ha tenido la tierra. Mujer abyecta, 
escupida fuera ¿qué te queda?.

Mujer, mujer que llevas en el vientre

el ser herido que te dona por doquier.

Mujer de apretados dientes,

mujer, mujer, decídete. 